\title{
TRANSSEXUALISM; A Sri Lankan experience: A descriptive study of epidemiological characteristics and management issues of transsexuals (TXLs) from a tertiary care clinic setting in Sri Lanka
}

\author{
Ginige $\mathrm{P}^{1}$, Malalagama $\mathrm{AS}^{2}$, Wijesinghe $\mathrm{PDLR}^{3}$, Gunawardena $\mathrm{N}^{4}$,
}

\begin{abstract}
Introduction: A transsexual (TXL) is an individual who seeks or has commenced a social transition from natal gender to desired gender. (1) This transition usually involves hormone treatment or sex reassignment surgery (SRS). Epidemiological characteristics of TXLs in Sri Lanka (SL) has not been studied to date.

Objective: The aim of this study is to describe the epidemiological characteristics and management of TXL clinic attendees at a tertiary care clinic setting in SL.

Method: This is a descriptive cross sectional study. Data was collected retrospectively from routine clinic notes on demographic and management characteristics of TXLs registered in the psychiatry clinics of Teaching Hospital Peradeniya from their incept to $31^{\text {st }}$ August 2018. Data were analyzed using SPSS-17.

Results: Total number of TXLs were 71 with $31 \%$ male to female (MTF) TXLs and $69 \%$ female to male (FTM) TXLs . Ratio between FTM to MTF was 2:1. Majority were Sinhala Buddhists between 31-35yrs. Unemployment was seen in $23 \%$. A comorbid psychiatric condition was diagnosed in $20 \%$ on presentation. The clinic has increasingly drained TXLs from almost all the provinces in SL over time. Hormonal treatment was received by $65 \%$ while $25 \%$ received some SRS. Majority were distressed due to deficiencies in organizing legal documents, hormone administration and SRS.

Conclusions: There is an increasing trend in help seeking by TXL individuals. Many were unable to have SRS. There is a major gap in service provision. The study creates awareness on the distribution of the TXLs in SL, their epidemiological characteristics and deficiencies in management.
\end{abstract}

Keywords: Gender dysphoria , transsexual, epidemiology, management, Sri Lanka,

Authors: ${ }^{1}$ Ginige P, MBBS, MD (Psych), Consultant Psychiatrist, Department of Psychiatry, Faculty of Medicine, University of Peradeniya, ${ }^{2}$ Malalagama AS, MBBS, MD (Psych), Consultant Psychiatrist, Base Hospital Diyatalawa. ${ }^{3}$ Wijesinghe PDLR, MBBS, Registrar in Psychiatry, Teaching Hospital,Peradeniya, ${ }^{4}$ Gunawardena N, MBBS, Temporary Lecturer, Department of Psychiatry, Faculty of Medicine, University of Peradeniya.

Copyright

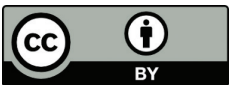

Corresponding author: Malalagama AS, shakunthini@yahoo.com, Orcid No. https://orcid.org/0000-0002-5507-9815

Acknowledgments: Dr S. Udaya Kumara Jayasooriya, Thejana Gunathilake, Temporary lecturers at Department of Psychiatry, Faculty of Medicine, University of Peradeniya.

Conflict of interest: None

Financial support: None

Originality: This is an original research conducted in the psychiatry clinics of Teaching Hospital, Peradeniya.

Submitted on: 15.10.2018; Accepted on: 19.11.2018 


\section{Full Article}

Introduction

Gender Dysphoria (GD) is the broad term used for the distress caused by incongruency between perceived and assigned genders in individuals who identify with a gender different from their gender assigned at birth.(1) A transsexual (TXL) is an individual who wishes to make the body as conformed as possible to the preferred sex through hormonal or surgical treatment.(1) Estimating global prevalence rates for GD is not easy. The cultural differences would influence behavioral expressions. TXLs with GD are the most easily countable subgroup as they present seeking help.(2) The research on TXLs is scanty and available data are mostly from the western world.

A meta-analysis by Arcelus et al reviewed 21 studies and concluded that the prevalence of 'transsexualism' in adult males was 1:14 705 and 1:38 461 in adult females.(3) In Asia, countries like Thailand and Singapore have a vast transgender community compared to the western countries; Singapore prevalence rates are high with prevalence rates of $35.2: 100,000$ or 1:2,900 male-to-female (MTF) and 12.0:100,000 or 1:8,300, female-to-male (FTM) TXLs.(4) GD is more prevalent among natal males.(5)

In most countries, crossing the normative gender boundaries creates moral forbiddance and censure rather than compassion. TXLs are subjected to violence and abuse more than any minority group. National Center for Transgender Equity and the National Gay and Lesbian Task Force in USA 2011 found in their survey that Lesbian, Gay, Bisexual and Transgender (LGBT) people are more than twice as likely as blacks or Jews to be subjected to violent hate crime.(6)

TXLs struggle with depression precipitated by stigma, shame and isolation by the society. In a national online sample of 1,093 transgender participants in the US, $44.1 \%$ had clinical depression and $33.2 \%$ had anxiety. Transgender women had a significantly higher prevalence of both depression and anxiety than transgender men.(7)

TXL people in Sri Lanka (SL) like their counterparts in the world are socially marginalized and deprived of basic rights. They are publicly ridiculed. They live in fear and shame from internalized transphobic issues as well as transphobia in the community. Human Rights Watch conducted a survey in 4 districts in SL among transgender and homosexual people between October 2015 and January 2016. They reported legal discrimination towards this group, especially with regards to identification documents, health care and interaction with police. (8) There are different views among the mental health professionals themselves about the acceptance of the condition as a disorder, locally. The general public is in the dark in relation to the mere existence of GD and the other psychological hardships of this community.(9) The religio-cultural and political scene in the country too is not very conducive to identify, accept and help the gender dysphoric.(8)

No published data was found on epidemiological factors associated with transgender population in SL in Google Scholar or PubMed from 1980 to date and we have addressed this unmet need. The study hopes to introduce the concept of transsexualism and report the demographic and management characteristics of the TXL population. Authors hope the results will help to formulate management guidelines for the country for this unique, ignored and maligned community.

Aim of this study is to describe the epidemiological characteristics and management of TXL clinic attendees at a tertiary care clinic setting in SL.

A second, qualitative arm of this study which is under way intends to look into the psychosocial adversities faced by the local TXL population.

\section{Methods}

Ethical clearance was obtained from the Ethics review committee, Faculty of Medicine, University of Peradeniya. In this retrospective study, clinical records of all the TXLs registered at weekly adult psychiatry clinic and sexual disorders clinic of Teaching Hospital Peradeniya (THP) were reviewed, from the time of inception on 16th of April 1985 and $15^{\text {th }}$ of June 2011 respectively to 31st of August 2018. All the patients diagnosed with Transsexualism were included except those with a psychotic illness.

Following the registration of subjects, a detailed assessment is carried out and the psychiatrist makes a diagnosis based on the diagnostic guidelines in the International Classification of Diseases- $10^{\text {th }}$ (ICD-10) version routinely.(10) Demographic information, details of gender transition, and management were extracted after careful perusal of the clinic records. 
Data were entered into an Excel spread sheet and analyzed using Statistical Package for the Social Sciences-17 (SPSS-17) using descriptive statistics.

Results

The total number of TXLs studied were 71. MTF TXLs comprised of 31\% and FTM TXLs, $69 \%$. Ratio between FTM TXLs to MTF TXLs was 2:1. All the patients had external and internal sex organs of birth sex. Societal gender role of all was that of the desired sex from the day they could remember and in various degrees depending on the differences in individual determinants such as the socio cultural back ground, the attitudes of family, the occupation demands and the personality traits of the patients etc. The age they recalled when they first had the awareness of living in the opposite gender's body was at $4-5 y r s$ in $31 \%$ of patients. Mannerism, behaviours and voices were more of the desired sex. All the FTM TXLs have attained menarche except one. All the MTF TXLs experienced the penile erections except one who has removed his penis by himself.

Though the clinic for sexual disorders was commenced in 1985 the first 3 registered patients of transsexualism presented in 2003. The number of patients registered increased after 2012(Graph 1). $46.47 \%$ of the individuals were referred to the clinic by another TXL.

\section{Graph 1: Number of TXLs registered in the clinic over the years}

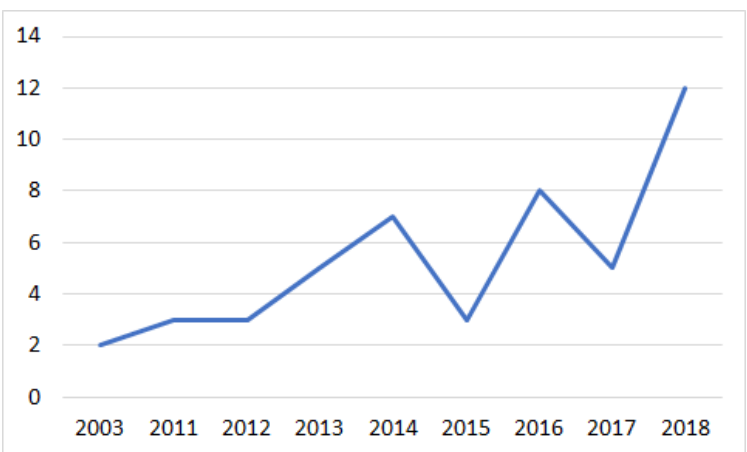

Age at presentation to the clinic ranged from 20 to 43 years (Table1). The mean age of presentation is younger in MTF (28.95yrs; $\mathrm{SD}=5.71$ ) than FTM (30.71yrs; SD=5.93) patients. There was no statistically significant difference between the mean age at presentation between FTM and MTF TXLs $(\mathrm{p}>0.1)$. Most TXL individuals were between ages 31-35yrs.
Table 1: Percentages of FTM and MTF TXLs according to age categories at presentation

\begin{tabular}{lrr}
$\begin{array}{l}\text { Age catgory } \\
(\mathrm{yrs})\end{array}$ & $\begin{array}{r}\text { Frequency } \\
\text { (Percentage) }\end{array}$ & $\begin{array}{r}\text { Frequency } \\
\text { (Percentage) }\end{array}$ \\
$16-20$ & FTM & MTF \\
\hline $21-25$ & $1(1.4)$ & $0(0)$ \\
\hline $26-30$ & $10(14.1)$ & $7(9.9)$ \\
\hline $31-35$ & $13(18.3)$ & $5(7.0)$ \\
\hline $36-40$ & $14(19.7)$ & $7(9.9)$ \\
\hline $41-45$ & $8(11.3)$ & $1(1.4)$ \\
\hline Total & $3(4.2)$ & $2(2.8)$ \\
\hline
\end{tabular}

The highest category of Sinhalese Buddhists of TXLs is probably a reflection of them being the majority in Sri Lanka (95\%). Muslims and Tamils represented $2.81 \%$ each.

Patients have presented from almost all the occupational categories while most were in the Technicians \& associate professionals and services and sales workers categories. Of the sample, 23\% were unemployed. Only $4 \%$ were engaged in professional occupations where one individual was a medical officer (Table 2).

Table 2: Occupations of TXLs classified according to the International Standard Classification of Occupations

2008

\begin{tabular}{lrr} 
Occupation & Frequency & Percentage \\
Managers & 1 & $1.4 \%$ \\
\hline Professionals & 3 & $4.22 \%$ \\
\hline $\begin{array}{l}\text { Technicians and associate } \\
\text { Professionals }\end{array}$ & 17 & $23.9 \%$ \\
\hline Clerical support workers & 6 & $8.5 \%$ \\
\hline Services and sales workers & 14 & $19.7 \%$ \\
\hline $\begin{array}{l}\text { Skilled agricultural, } \\
\text { forestry and fishery }\end{array}$ & 4 & $5.6 \%$ \\
workers & & \\
\hline Craft and related trade & 2 & $2.8 \%$ \\
workers & & \\
\hline Plant and machine & 1 & $1.40 \%$ \\
operators and assemblers & & \\
\hline Elementary occupations & 6 & $8.5 \%$ \\
\hline Armed forces occupations & 2 & $2.8 \%$ \\
\hline None & 16 & $22.5 \%$ \\
\hline Students & 3 & $4.2 \%$
\end{tabular}

TXLs presented from all the provinces except the Uva province. Interestingly the highest percentage of individuals presented to this central province 
centre was from the Western province (Figure 1).

Figure 1: Percentage of TXLs presented from each province in SL

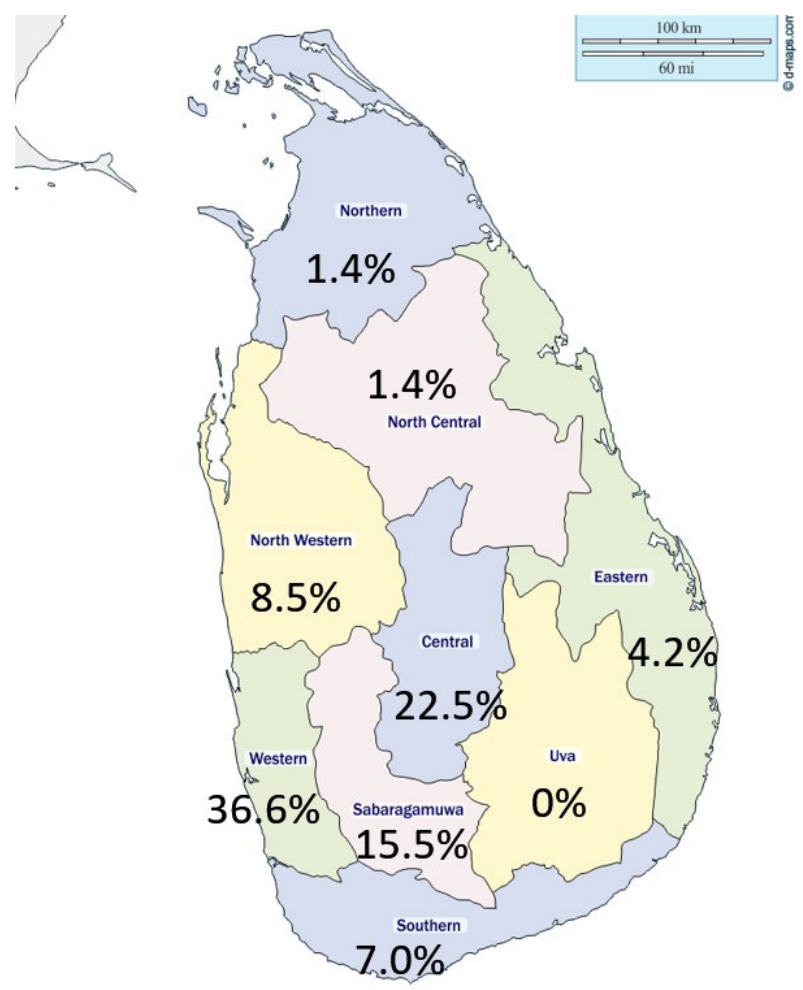

Nearly one fifth of TXLs (20\%) had a comorbid psychiatric condition on presentation and depression was the commonest (17\%) (Table 4). 3\% had Anxiety disorders, 3\% had Mental and Behavioural disorders due to alcohol use while $1 \%$ had Bipolar affective disorder.

The study group was in various stages of SRSs depending on the availability of a willing surgeon/ plastic surgeon or a gynaecologist, financial stability and family support (Table 4).

Table 4: Treatments used by TXLs in the sample

\begin{tabular}{lrr} 
Treatment & Frequency & $\begin{array}{l}\text { Percentage of } \\
\text { TXLs who used } \\
\text { the treatment }\end{array}$ \\
Hormonal treatment & 46 & $64.8 . \%$ \\
\hline Mastectomy & 15 & $21.1 \%$ \\
\hline Hysterectomy & 3 & $4.2 \%$ \\
\hline Breast implant & 1 & $1.4 \%$ \\
\hline Orchidectomy & 1 & $1.4 \%$ \\
\hline
\end{tabular}

Legal identification documents such as national identity card, passports and birth certificates were completed by $13 \%$. But the majority have not completed their paper work.

It is interesting to see that $63 \%$ of FTM TXLs were engaged in contact sports, athletics and martial arts and that $14 \%$ were national or district level players.

There was one FTM TXL who is a boxing player representing SL at international tournaments. Forty-five per cent (45\%) of MTF TXLs engaged in music, arts or drama. One MTF TXL was a media speaker and a spokesperson for TXLs. Only one MTF reported of sexual assault. 38\% were working with the NGOs Equal grounds or Wenasa.

\section{Discussion}

Determining the prevalence of TXLs has become a challenge worldwide. Social stigma and transphobia exclude them from their families, social circles and sometimes expel them from their occupations making open acceptance of their condition difficult. The high cost incurred for gender transition is also another barrier for the "coming out" process. (4) The socio-cultural background in SL is hostile for TXLs probably due to the lack of awareness of the condition. Calculating the true prevalence of TXLs is thus impractical. But epidemiological investigations into this group at least when they present for services would give a chance to identify their needs and problems which in turn would help the medical fraternity and authorities to build services.

The number of TXLs seeking help has increased worldwide due to increased awareness through the web, social media and by TXL activists and due to expansion of services for them.(3) Our study reflects this trend which shows a significant rise in the number of patients registered in the clinic over one and half decades, possibly due to local TXL population slowly being informed of the availability of services at Peradeniya centre through the earlier pioneering clients of the clinic. There are two psychiatrists who are playing a leading role in transgender management in the country. The static period from 2003 to 2011 in the presentation to clinic denotes the unavailability of the psychiatrist at the clinic. (Graph 1). It is an area the majority of the mental health professionals are reluctant to tread on. Lack of proper training in GD management and own transphobia could be reasons for the observed lack of involvement. 
FTM to MTF ratio in this sample was 2:1, which is opposite to the international figure of 1:2.2. (11) It is probable that FTM TXLs are higher in number as the males have higher social cultural privileges and occupational and educational opportunities than females in SL. However, this aspect needs further exploration with a more representative national sample in a qualitative analysis. The highest prevalence of TXLs presenting to the clinic was between 31-35 years of age which reflects the fact that they present when they are independent from their families as coming out is difficult as long as they are bound to their families.

The fact that $23 \%$ of the sample was unemployed is highly significant as gender transition procedures are costly and these individuals might not be in a position to access them.

The central province clinic drained the highest number of patients from the Western province. (Figure 1). The TXL population had two choices of clinics for the whole country at the time of the study. This calls for attention to open up services in Tertiary care centers for TXLs.

TXLs seems to be engaging in leisure activities according to preferred gender as indicated by FTM engaging in sports and martial arts and MTF in aesthetic subjects.

Depression is the commonest psychiatric disorder found among TXL individuals even in a multicenter study done in 4 European countries and it is replicated in this study. (12)

The TXLs of the study have the observed behavioural pattern of seeking help during the peak of requirements and not having regular contact with service providers. They also change their contact details which makes it further difficult to trace them. Therefore the progress of hormone therapy, SRS and the current status in transition is unavailable for some TXLs. This challenge is reported in international studies as well. (4) Another limitation of this study is that data on marital status, sexual orientation and parenthood of TXLs could not be elicited.

The psychosocial adversities and traumatic experiences they faced are going to be assessed in the second half of our study.

Majority of TXLs have not completed the legal transition which is a concern of their future prospects. Obtaining recognition of the preferred gender before the law is a key element in management. About 8 countries, Bangladesh, India, Pakistan, Nepal, Malta, New Zealand, Australia and Netherlands now legally recognize more than two genders. $(13,14,15)$ Ministry of Health SL has issued a gender recognition certificate (GRC) following extensive collaborative work by major stake holders in transsexualism.(16)

International professional bodies and experts have considered the importance of respecting and conforming to the gender identities of individuals. (17) Formation of National Good Practice guidelines for Sri Lanka with the participation of representatives of all the stake holders in TXL care is imperative. An attitudinal change in all relevant professional groups is quite essential with proper education of the public as well to prevent an uproar of the ill-informed.

\section{Conclusions}

There is an increasing trend in help seeking by TXL individuals in SL. Majority present when they are independent from their families due to sociocultural barriers imposed. Many were unable to have SRS and legal recognition of their gender transition. There is a major gap in service provision, services mainly concentrated to Central and Western provinces. The study creates awareness on the distribution of the TXLs in SL, their epidemiological characteristics and deficiencies in management and would help medical fraternity and authorities to plan culturally appropriate management protocols.

\section{References}

1. American Psychiatric Association: Diagnostic and Statistical Manual of Mental Disorders, Fifth Edition. Arlington, VA, American Psychiatric Association, 2013.

2. Zucker KJ, Lawrence AA. Epidemiology of Gender Identity Disorder: Recommendations for the Standards of Care of the World Professional Association for Transgender Health. International Journal of Transgenderism. 2009; 11(1):8-18.

3. Zucker JK. Epidemiology of gender dysphoria and transgender identity. Sexual Health. 2017. 14. 10.1071/ SH17067.

4. De Cuypere G, Van Hemelrijck M, Michel A, et al. Prevalence and demography of transsexualism in Belgium. European Psychiatry 22 (2007) 137e141.

5. Kenneth J. Zucker \& Anne A. Lawrence (2009) Epidemiology of Gender Identity Disorder: Recommendations for the Standards of Care of the World Professional Association for Transgender Health, International Journal of Transgenderism, 11:1, 8-18, DOI: $10.1080 / 15532730902799946$ 
6. Grant JM, Mottet LA, Tanis J. Injustice at every turn: a report of the National Transgender Discrimination Survey. The National Gay and Lesbian Task Force and the National Center for Transgender Equality. 2011.

7. Bockting WO, Miner MH, Swinburne Romine RE, et al.: Stigma, mental health, and resilience in an online sample of the US transgender population. Am J Public Health 2013; 103:943-951

8. Human Rights Watch. All Five Fingers Are Not the Same" Discrimination on Grounds of Gender Identity and Sexual Orientation in Sri Lanka.2016.

9. Ginige, P.2016. Woman-manly or Man-womanly: Gender Dysphoria in Sri Lanka SLCPsych News Letter: 5.

10. World Health Organization. The ICD-10 classification of mental and behavioural disorders: clinical descriptions and diagnostic guidelines. Geneva, 1992.

11. Becerra-Fernández, A., Rodríguez-Molina, J.M., AsenjoAraque, N. et al. Prevalence, Incidence, and Sex Ratio of Transsexualism in the Autonomous Region of Madrid (Spain) According to Healthcare Demand. Arch Sex Behav (2017) 46: 1307. https://doi.org/10.1007/s10508017-0955-z.

12. Heylens, G., Elaut, E., Kreukels, B., Paap, M., Cerwenka, S., Richter-Appelt, H., De Cuypere, G. (2014). Psychiatric characteristics in transsexual individuals: Multicentre study in four European countries. British Journal of Psychiatry, 204(2), 151-156. doi:10.1192/ bjp. bp.112.121954.

13. Human Rights Watch. Letter to Lok Sabha on the Rights of Transgender Persons Bill (homepage on the internet). C2018 (cited 2018 October 20). Available from http:// www.hrw.org/news/2015/07/20/letter-lok-sabha-rightstransgender-persons-bill

14. Human Rights Watch. Allegation letter regarding the legal gender recognition procedure in Ukraine, as specified in Order No. 60 of the Ministry of Health of Ukraine (homepage on the internet). C2018 (cited 2018 October 20). Available from https://www.hrw.org/ news/2015 /04/27/allegation-letter-regarding-legalgender-recognition-procedure-ukraine-specified

15. Human Rights Watch. Dispatches: Nepal's Transgender Passport Progress (homepage on the internet). C2018 (cited 2018 October 20). Available from http://www.hrw. org/news/2015/08/10/dispatches-nepals-transgenderpassport-progress

16. Health circulars, Ministry of Health, Sri Lanka. Issuing of Gender Recognition Certificate for Transgender Community (homepage on the internet). C2014 (cited October 30). Available from http://www.health. gov.lk $/ \mathrm{CMS} / \mathrm{cmsmoh} 1 /$ viewcircular.php?cno=0134/2016\&med=english

17. World professional association for transgender Health (homepage on the internet) Available from https:// wpath.org/ 